\title{
Vitamin D and Diabetic Neuropathy in Patients with Type 2 Diabetes Mellitus: A Current Perspective
}

Mohamed Shaheen Anodiyil $^{1 *}$, Shajitha Thekke Veettil ${ }^{2}$, Mohammed Ali Kalathingal ${ }^{3}$

${ }^{\mathrm{I}}$ Dirctorate of Operations, Al Rayyan Health Centre, Primary Health Care Corporation, Doha, Qatar

${ }^{2}$ Dirctorate of Clinical Affairs, Department of Clinical Research, Primary Health Care Corporation, Doha, Qatar

${ }^{3}$ Dirctorate of Operations, Al Daayen Health Centre, Primary Health Care Corporation, Doha, Qatar

DOI: $10.36347 /$ sjams.2021.v09i01.028

| Received: 30.11 .2020 | Accepted: 20.01.2021 | Published: 29.01.2021

*Corresponding author: Dr. Mohamed Shaheen Anodiyil

\section{Abstract}

Type 2 diabetes mellitus (DM) is a global epidemic associated with severe vascular complications development Diabetic neuropathy is the most common chronic complication of DM that worsens patients' quality of life and prognosis. Therefore, studies dealing with DM and diabetic neuropathy underlying mechanisms are extremely relevant. This review discusses current views on possible association between vitamin D deficiency and diabetic peripheral neuropathy (DPN) in patients with type 2 diabetes. It is reported that Vitamin D is involved in the development of DPN in type 2 diabetic patients, and vitamin D deficiency is very likely to be associated with DPN in type 2 diabetic patients. Further interventional studies are needed to validate the association between vitamin $\mathrm{D}$ deficiency and DPN.

Keywords: Vitamin D, diabetic peripheral neuropathy, type 2 diabetes mellitus.

Copyright $(\mathcal{C}) 2021$ The Author(s): This is an open-access article distributed under the terms of the Creative Commons Attribution 4.0 International License (CC BY-NC 4.0) which permits unrestricted use, distribution, and reproduction in any medium for non-commercial use provided the original author and source are credited.

\section{INTRODUCTION}

Diabetes is a chronic, serious disease that occurs either when the pancreas does not produce enough insulin, or when the body cannot effectively use the insulin it produces. Diabetes is one of four priority noncommunicable diseases (NCDs) and an important public health problem, targeted for action by world health leaders. According to World Health Organization (WHO), the global prevalence of diabetes was $8.5 \%$ in the adult population. Compared to 108 million in 1980, an estimated 422 million adults were living with diabetes in 2014 and the number will rise to 366 million in 2030 [1].

Diabetes of all types can lead to complications in many parts of the body and can increase the overall risk of dying prematurely. Diabetic peripheral neuropathy (DPN) is one of the major complications and it is characterized by pain, sensory loss and disability due to weakness. Severe undiagnosed sensory loss can lead to foot ulcers, which can lead to amputation. DPN can go undiagnosed until the patient presents with an ulcer [2].

The prevalence of DPN in people with diabetes has been reported to be up to $50 \%[3,4]$. The average prevalence of diabetes in the middle east and north Africa (MENA) region was 9.7\% [5]. Estimates of the prevalence of DN in people with T2DM vary from $17 \%$ to $53 \%$ in the Middle East and North Africa (MENA) region,7-9 27\% to $32 \%$ in Europe, $10-1221 \%$ to $45 \%$ in the United States and $17 \%$ to $62 \%$ in China. This high variability may be attributed to the heterogeneity of the populations studied and differing criteria for the diagnosis of DN [6].

The pathological progress of DPN is still not completely clear. It's essential to identify potential risk factor in diabetes mellitus for the better understanding of the mechanism of DPN. Some epidemiological studies have indicated that the high level of blood glucose and glycated hemoglobin, the duration of diabetes, elevated albumin excretion rates, obesity and hypertension are the main risk factors for DPN $[7,8]$.

Vitamin D has an established role in calcium and bone metabolism; however, more recently associations with vitamin D deficiency and risk of developing diabetes, diabetes complications, and cardiovascular disease have all been acknowledged [9]. Vitamin D has already been proven to be associated with the regulation of bone metabolism in previous 
Mohamed Shaheen Anodiyil et al; Sch J App Med Sci, Jan, 2021; 9(1): 142-148

studies, while, several epidemiological studies also indicate that vitamin D has a strong association with multiple autoimmune diseases [10]. Appropriate supplementation of vitamin D may play a potential therapeutic role in preventing the severity and progression of type 1 diabetes mellitus and type 2 diabetes mellitus [10]. 25-Hydroxyvitamin D [25(OH) $\mathrm{D}$ ], a biomarker of vitamin $\mathrm{D}$, is measured in the blood sample to monitor the vitamin D level in patients [11]. The concentration of 25-Hydroxyvitamin D ranges from 20 to $30 \mathrm{ng} / \mathrm{ml}$ or 50 to $75 \mathrm{nmol} / \mathrm{L}$ is considered as vitamin $\mathrm{D}$ insufficiency. Vitamin $\mathrm{D}$ deficiency is defined as $25(\mathrm{OH}) \mathrm{D}$ less than $20 \mathrm{ng} / \mathrm{ml}$ or $50 \mathrm{nmol} / \mathrm{L}$ $[12,13]$. Increasing researches have suggested that low vitamin $\mathrm{D}$ level, in addition to result in rickets in infants and chondrosteoma in adults as we all known, may have a potential role in the generation of DM and its underlying diseases [14,15]. Vitamin D deficiency, a common symptom in diabetic patients who has distal symmetrical polyneuropathy, has been associated with type 1 or 2 diabetes and its microvascular and macrovascular complications [16].

A systematic review conducted in Qatar reported that about $90 \%$ of the population might have insufficient levels of serum vitamin D [17]. The weighted-average level $45.3 \pm 14.3 \mathrm{nmol} / \mathrm{L}$ was below the optimal level of serum vitamin $\mathrm{D}(75 \mathrm{nmol} / \mathrm{L})$ advocated by the National Academy of Sciences Institute of Medicine (IOM) [18]. Levels around 50-75 $\mathrm{nmol} / \mathrm{L}$ are considered insufficient. Vitamin D deficiency is common in patients with diabetes and is associated with the presence and the severity of sensory neuropathy [18]. Vitamin D deficiency has been shown to be an independent risk factor for DPN [19, 20]. Vitamin D supplementation has been reported to significantly reduce DPN and painful symptoms [21, 22].

\section{Vitamin D, nerves, and diabetic neuropathy}

Previously studies of vitamin D have largely focused on bone health and calcium metabolism; however, an increasing body of evidence particularly over the past two decades implicates a role of vitamin D in the nervous system [23, 24]. Multiple neurodegenerative diseases including multiple sclerosis [25-29] and Parkinson's disease [30], as well as cognitive decline in the elderly [31], have been linked with declining vitamin $\mathrm{D}$ status. There are some data to suggest that treatment with high doses of vitamin D3 slows down the progression of disability linked to multiple sclerosis [32]; however, further larger interventional studies are required to truly assess any therapeutic benefit [33].

Nerve growth factor (NGF) was first identified as being essential for the development of nociceptive primary neurons and later found to have a role in inflammatory hyperalgesia in adults [34]. NGF is a neurotrophic factor which is synthesized initially as pro-
NGF, prior to being cleaved by intracellular proteases before being translocated to the rough endoplasmic reticulum and is cleaved a second time by extracellular proteases to produce the active form [34]. NGF is responsible for the development and maintenance of neurons in several regions in the central nervous system $[34,35]$. Importantly, topical application of NGF in diabetic foot ulcers has resulted in promotion of healing [36]. NGF has previously been successfully studied in phase 2 clinical trials [37] but showed a lack of efficacy in a phase 3 study for DPN [38].

The prevalence of DPN can be as high as $50 \%$ [39] and symptomatic diabetic neuropathy can affect approximately $30 \%$ of diabetic patients with neuropathy [40]. Currently there are no licensed therapies which may alter the natural history of DPN; therefore, symptom control remains the mainstay of DPN management. Even for symptom relief, effective treatment continues to remain a major challenge. Anticonvulsants and antidepressants are first-line therapy with a $50 \%$ reduction in pain considered a good outcome [41]. In the largest observational study to date of diabetic patients in a primary care cohort in the UK ( $\mathrm{n}=15,692)$, the prevalence of painful symptoms and painful DPN was $34 \%$ and $21 \%$ in South Asians and Europeans, respectively [42]. Additionally the adjusted risk of painful neuropathic symptoms in type 2 diabetes was double that of type 1 diabetes (OR, 2.1; 95\% CI, $1.7-2.4$; P 0.001 ) and women had a $50 \%$ increased adjusted risk of painful symptoms compared with men (OR, 1.5; 95\% CI, 1.4-1.6; P\0.0001). Furthermore, despite a lower prevalence of neuropathy in South Asians (14\%) compared to Europeans (22\%) and African Caribbeans (21\%; P\0.0001), painful symptoms were greatest in South Asians (38\% vs. 34\% vs. 32\%, $\mathrm{P} \backslash 0.0001)$. South Asians without neuropathy maintained a $50 \%$ increased risk of painful neuropathic symptoms compared with other ethnic groups (P\0.0001). These differences may partly be explained in relation to vitamin D deficiency as these groups have been shown to have excess vitamin D deficiency [43]. Other studies have assessed ethnic differences in DPN in a US population with variations noted in risk for DPN and diabetic autonomic neuropathy [44]. However, in an Australian study there were no significant differences between ethnic groups [45] although the ethnic mix of the last two studies differs from that in the UK.

An increasing body of data suggests that vitamin $\mathrm{D}$ may have not only analgesic properties but also additional neuroprotective benefits. Vitamin D deficiency and insufficiency are associated with various pain syndromes and low levels of vitamin D correlated with the presence of peripheral neuropathy in primary Sjogren's syndrome which can lead to a small fiber neuropathy [46]. Vitamin supplementation has been shown to improve musculoskeletal pain and nontraumatic backpain in some studies [47]. However, there is a prominent contrast in treatment effects 
Mohamed Shaheen Anodiyil et al; Sch J App Med Sci, Jan, 2021; 9(1): 142-148

between randomized, double-blind trials that minimized bias and those with designs known to be subject to bias [47] with better treatment effects noted in the latter. Therefore, the overall evidence for the use of vitamin D for chronic pain in adults is poor because of low-quality and insufficient RCTs [47].

Pain thresholds of multiple etiologies have been reported to be lowered with vitamin D deficiency and elevated when the vitamin D deficiency is corrected [48]. Previous observational studies have demonstrated a significant link between vitamin D deficiency and DPN [49-51]. In the National Health and Nutrition Examination Survey (NHANES) 2001-2004, an unweighted sample of 591 subjects with diabetes demonstrated a significant association between vitamin $\mathrm{D}$ deficiency and both paresthesia (OR, 2.12; 95\% CI, 1.17-3.85) and numbness (OR, 2.04; 95\% CI, 1.183.52) after adjusting for obesity, co-morbidities, use of medications for neuropathy, diabetes duration, and glycemic control [49]. Furthermore, in a prospective observational study conducted by Skalli et al. [51] in 111 consecutive ambulatory patients with type 2 diabetes an association between vitamin $\mathrm{D}$ deficiency and peripheral diabetic neuropathy was found [51]. Although both subjects with and without DPN were deficient, those with DPN had approximately $4 \mathrm{ng} / \mathrm{mL}$ lower $25(\mathrm{OH}) \mathrm{D}$ levels. In a further cross-sectional study by Shehab et al. [50], vitamin D deficiency was an independent risk factor for DPN assessed using the neuropathy symptom score and other clinical and electrophysiological measures of DPN. The duration of diabetes was higher in the group with peripheral neuropathy as was elevated low-density lipoproteincholesterol (LDL). This latter observation may be of relevance as both vitamin $\mathrm{D}$ and cholesterol share a common metabolic pathway through 7dehydrocholestrol. In a more recent study conducted in a small homogenous population in rural Turkey, reduced serum $25(\mathrm{OH}) \mathrm{D}$ was associated with DPN [52]; interestingly, neither Vitamin D Receptor (VDR) nor VDR-binding protein differed between those with and without DPN [52].

Large nerve fiber deficits have also been associated with vitamin D status in diabetes mellitus [53]. In an age, sex, body mass index (BMI), height, and disease duration matched cohort $(n=33)$ of patients with diabetes, $25(\mathrm{OH}) \mathrm{D}$ was significantly lower in the DPN group $(21.2 \pm 11.5$ vs. $13.5 \pm 5.1 \mathrm{ng} / \mathrm{mL}, \mathrm{P}=$ 0.001) [53]. After further adjustment for all studied variables, serum vitamin D had an independent and inverse association with both DPN presence and severity, as each $1 \mathrm{ng} / \mathrm{mL}$ increase in serum 25(OH)D was correlated with $2.2 \%$ and $3.4 \%$ decrease in the presence and severity of nerve conduction studies (NCV) impairment, respectively [53]. In a metaanalysis of six studies that involved a total of 1484 patients with type 2 diabetes, vitamin D deficiency (120 $\mathrm{ng} / \mathrm{mL}$ ) was significantly associated with an increased risk of DPN [54]. The OR was 2.88 (95\% CI, 1.844.50; P\0.00001) with an adjusted OR of 2.68 (95\% CI, $1.67-4.30$; P\0.0001) in a sub analysis of three studies, suggesting that "vitamin D deficiency is very likely to be associated with DPN in type 2 diabetic patients' '[54].

To date clinical trials of vitamin D intervention for DPN are limited. A single case report has shown reversal of symptoms in severe intractable painful diabetic neuropathy with the administration of 50,000 IU ergocalciferol (vitamin D2) weekly with almost complete resolution by 4 weeks [55]. Even though the patient was not severely deficient with a baseline $25(\mathrm{OH}) \mathrm{D}$ of approximately $16 \mathrm{ng} / \mathrm{mL}$, the subsequent pain relief from the weekly ergocalciferol dose enabled the discontinuation of oxycodone [55]. Lee et al. [56] conducted an open-label uncontrolled study in patients with vitamin D deficiency and 51 patients with painful DPN. After treatment with oral cholecalciferol (vitamin D3) at a mean dose of 2059 IU daily for 3 months there was an improvement of approximately $50 \%$ on the Visual Analogue Scale (pain) [56]. Although the placebo effect can be considerable in trials of therapeutic agents in painful DPN, the maximal placebo effect expected would be no more than approximately $30 \%$ [57]. Indeed a 50\% pain reduction is considered to be efficacious when evaluating interventions in painful DPN [57]. Valensi et al. [58] conducted a double-blind RCT of a compound (QR-333) containing a vitamin D analogue and showed positive effects on numbness, jolting pain, and irritation in subjects with painful DPN. However, the outcomes of this study are somewhat confounded as QR-333 contained quercetin, a flavonoid with aldose reductase inhibitor effects, which is one of the key pathogenetic pathways causing diabetic neuropathy.

One of the key 'hard endpoints' of DPN is foot ulceration, which may eventually lead to lower limb amputation and significant morbidity and mortality [59]. In a cross-sectional study of diabetic patients without $(\mathrm{n}=162)$ and with $(\mathrm{n}=162)$ plantar ulcers, lower $25(\mathrm{OH}) \mathrm{D}$ status was associated with plantar ulceration in patients with diabetes [60]. In a further study by Tiwari et al. [61], vitamin D deficiency was more prevalent and severe in patients with diabetic foot infection. Cases of foot infection $(n=125)$ had a greater risk of vitamin D deficiency $(25(\mathrm{OH}) \mathrm{D} \backslash 20 \mathrm{ng} / \mathrm{mL})$ than controls $(\mathrm{n}=164)$ with an OR of $1.8(95 \% \mathrm{CI}, 1.1-3.0$; $\mathrm{P}=0.02)$ and the risk of severe vitamin $\mathrm{D}$ deficiency $(25(\mathrm{OH}) \mathrm{D} \backslash 10 \mathrm{ng} / \mathrm{mL})$ was significantly higher in cases than in controls with an OR of 4.0 (95\% CI, 2.4-6.9; $\mathrm{P} \backslash 0.0001)$ [61].

\section{DISCUSSION}

This present review aiming to estimate the association between serum 25(OH)D levels and DPN in patients with type 2 diabetes. Previous study results suggest that vitamin D is involved in the development 
of DPN in type 2 diabetic patients, and vitamin D deficiency is associated with increased risk of DPN. Thus, vitamin D deficiency is a biomarker of DPN and it has some indications for the prevention or treatment of diabetic neuropathy. DPN is a common complication in patients with diabetes, and it can result in increased risks of disability, cardiovascular diseases, and mortality. Though multiple possible etiologies are proposed for DPN, such as hyperglycemia-induced oxidative stress, inflammation and neuronal ischemia, this mechanism is still not completely clear. A metaanalysis done by W. S. Lv et al. [54], find certain evidence for the association between serum 25(OH)D levels and DPN in patients with type 2 diabetes. Currently, there is lack of effective therapies for DPN. The identification of the associations of DPN with modifiable risk factors can provide us some implications for the development of new therapies for DPN. Since vitamin D deficiency is a modifiable risk factor for DPN, vitamin D supplement maybe an effective treatment for type 2 diabetic with DPN and vitamin $\mathrm{D}$ deficiency. However, there are no relevant trials aiming to assess the vitamin D supplement for DPN patients. Further clinical trials are needed to validate the role of vitamin $\mathrm{D}$ supplementation in the prevention or treatment of diabetic neuropathy. Serum $25(\mathrm{OH}) \mathrm{D}$ is the circulating form of vitamin $\mathrm{D}$ that is measured in the blood and clinically used to establish and monitor patients' vitamin D status $[62,63]$. It has been shown that $25(\mathrm{OH}) \mathrm{D}$ can reduce $\beta$ cell dysfunction by depressing diabetes-associated inflammation in the pancreas and restoring impaired insulin production [64, 65]. Other studies also show that $25(\mathrm{OH}) \mathrm{D}$ can counteract increased insulin resistance, and low serum $25(\mathrm{OH}) \mathrm{D}$ level is a maker of insulin resistance and hyperglycemia [64, 66, 67]. Both inflammation and hyperglycemia are suggested to be involved in the development of DPN [68-70]. Thus, vitamin D deficiency may increase risk of DPN via the subsequent impacts of inflammation and hyperglycemia caused by vitamin $\mathrm{D}$ deficiency. However, the mechanism involved in the association between serum $25(\mathrm{OH}) \mathrm{D}$ levels and DPN in patients with type 2 diabetes is still unclear, and further studies are needed to explore it.

Most of the studies used in the meta-analysis were cross-sectional design, which was unable to consider all common confounding factors and might cause certain risk of bias. Compared with cohort studies, cross-sectional design also has low power to address the causal effects. Thus, to get a more precise assessment of the impact of vitamin D deficiency on DPN risk in type 2 diabetes, more prospective, welldesigned cohort studies are necessary. Finally, our study only assessed the association between serum $25(\mathrm{OH}) \mathrm{D}$ levels and DPN risk in type 2 diabetes since there was no relevant study from type 1 diabetic patients. Future studies can further assess the association between vitamin $\mathrm{D}$ deficiency and DPN risk in type 1 diabetic patients [54].

\section{CONCLUSION}

In conclusion, this review suggests that vitamin D is involved in the development of DPN in type 2 diabetic patients, and vitamin $\mathrm{D}$ deficiency is very likely to be associated with increased risk of DPN. It remains unknown if supplementation of vitamin D to normal or non-deficient levels alters pathogenetic processes related to diabetic microvascular complications. To get a more precise assessment of the impact of vitamin D deficiency on DPN risk in type 2 diabetes, more prospective, well-designed cohort studies are necessary.

\section{REFERENCES}

1. Global report on diabetes 21 April 2016. WHO team? 9789241565257

https://www.who.int/publications-detail/globalreport-on-diabetes

2. Boulton AJ, Vinik AI, Arezzo JC, Bril V, Feldman EL, Freeman R. Diabetic neuropathies: a statement by the American Diabetes Association. Diabetes Care. 2005; 28:956-962.

3. Tesfaye S. Recent advances in the management of diabetic distal symmetrical polyneuropathy. J Diabetes Investig. 2011; 2:33-42.

4. Young MJ, Boulton AJ, MacLeod AF, Williams DR, Sonksen PH. A multicentre study of the prevalence of diabetic peripheral neuropathy in the United Kingdom hospital clinic population. Diabetologia 1993; 36:150-154.

5. IDF-MENA. World Diabetes Atlas. 2014.

6. Ponirakis G, Elhadd T, Chinnaiyan S, Dabbous Z, Siddiqui M, Al-Muhannadi H, Petropoulos IN, Khan A, Ashawesh KAE, Dukhan KMO, Mahfoud ZR, Murgatroyd C, Slevin M \& Malik RA. Prevalence and management of diabetic neuropathy in secondary care in Qatar. Diabetes Metab Res Rev. 2020 May;36(4):e3286. doi: 10.1002/dmrr.3286. Epub 2020 Jan 23. PMID: 31913560.

7. Tesfaye S, Selvarajah D. Advances in the epidemiology, pathogenesis and management of diabetic peripheral neuropathy. Diabetes Metab Res Rev. 2012;28(Suppl 1):8-14. http://dx.doi.org/10.1002/dmrr.2239 [PubMed].

8. Yagihashi S. Recent advances in clinical practice and in basic research on diabetic neuropathy. Brain Nerve. 2011;63(6):571-82. http://dx.doi.org/10.11477/mf.1416100928 [PubMed].

9. Alam U, Arul-Devah V, Javed \&, Malik RA. Vitamin D and Diabetic Complications: True or False Prophet? Diabetes Ther. 2016 Mar;7(1):1126. doi: 10.1007/s13300-016-0159-x. Epub 2016 Mar 12. PMID: 26971351; PMCID: PMC4801816.

10. Yang CY, Leung PS, Adamopoulos IE, Gershwin ME. The implication of vitaminD and autoimmunity: a comprehensive review. Clin Rev Allergy Immunol. 2013;45(2):217-26. 
Mohamed Shaheen Anodiyil et al; Sch J App Med Sci, Jan, 2021; 9(1): 142-148

http://dx.doi.org/10.1007/s12016-013-8361-3

[PubMed].

11. Smith TJ, Lanham-New SA, Hart KH. Vitamin D in adolescents: are current recommendations enough? J Steroid Biochem Mol Biol 2017. http://dx.doi.org/ 10.1016/j.jsbmb.2017.02.010 [PubMed].

12. Forouhi NG, Ye Z, Rickard AP, Khaw KT, Luben R, Langenberg C. Circulating 25-hydroxyvitamin $\mathrm{D}$ concentration and the risk of type 2 diabetes: results from the European Prospective Investigation into Cancer (EPIC)-Norfolk cohort and updated meta-analysis of prospective studies. Diabetologia. 2012;55(8):2173-82.

http://dx.doi.org/10.1007/s00125-012-2544y[PubMed].

13. Pramyothin P, Holick MF. Vitamin D supplementation: guidelines and evidence for subclinical deficiency. Curr Opin Gastroenterol. 2012;28(2):139-50. http:// dx.doi.org/10.1097/MOG.0b013e32835004dc [PubMed].

14. Benrashid M, Moyers K, Mohty M, Savani BN. Vitamin D deficiency, autoimmunity, and graftversus-host-disease risk: implication for preventive therapy. Exp Hematol 2012;40(4):263-7. http://dx.doi.org/10.1016/j.exphem.2012.01.006 [PubMed].

15. Harinarayan CV. Vitamin D and diabetes mellitus. Hormones (Athens). 2014;13(2):163-81 [PubMed].

16. Bell DS. Reversal of the symptoms of diabetic neuropathy through correction of vitamin D deficiency in a type 1 diabetic patient. Case Rep Endocrinol. 2012;2012:165056. http://dx.doi.org/10.1155/2012/165056 [PubMed].

17. Badawi A, Arora P, Sadoun E, Al-Thani AA, Thani MH. Prevalence of vitamin d insufficiency in qatar: a systematic review. J Public Health Res 2012; 1:229-235

18. Ross AC, Manson JE, Abrams SA, Aloia JF, Brannon PM, Clinton SK. The 2011 Dietary Reference Intakes for Calcium and Vitamin D: what dietetics practitioners need to know. J Am Diet Assoc 2011; 111:524-527.

19. Shehab D, Al-Jarallah K, Mojiminiyi OA, Al Mohamedy H, Abdella NA. Does Vitamin D deficiency play a role in peripheral neuropathy in Type 2 diabetes? Diabet Med 2012; 29:43-49.

20. Soderstrom LH, Johnson SP, Diaz VA, Mainous AG, 3rd. Association between vitamin D and diabetic neuropathy in a nationally representative sample: results from 2001-2004 NHANES. Diabet Med. 2012; 29:50-55.

21. Bell DS. Reversal of the Symptoms of Diabetic Neuropathy through Correction of Vitamin D Deficiency in a Type 1 Diabetic Patient. Case Rep Endocrinol 2012; 2012:165056.

22. Shehab D, Al-Jarallah K, Abdella N, Mojiminiyi OA, Al Mohamedy H. Prospective evaluation of the effect of short-term oral vitamin $d$ supplementation on peripheral neuropathy in type 2 diabetes mellitus. Med Princ Pract 2015; 24:250256.

23. Holmøy T, Moen SM. Assessing vitamin D in the central nervous system. Acta Neurol Scand Suppl.2010;122:88-92.

24. Alam U, Asghar O, Malik RA. Are vitamin D and B deficiency relevant to the pathogenesis and treatment of diabetic neuropathy? Future Neurol.2012;7:235-8.

25. Simon KC, Munger KL, Ascherio A. Vitamin D and multiple sclerosis: epidemiology, immunology, and genetics. Curr Opin Neurol. 2012;25:246-51.

26. Simon KC, Munger KL, Xing Y, Ascherio A. Polymorphisms in vitamin $\mathrm{D}$ metabolism related genes and risk of multiple sclerosis. Mult Scler.2010;16:133-8.

27. Van der Mei IA, Ponsonby AL, Dwyer T. Vitamin $\mathrm{D}$ levels in people with multiple sclerosis and community controls in Tasmania, Australia. J Neurol. 2007;254:581-90.

28. Simpson S Jr, Taylor B, Blizzard L. Higher 25hydroxyvitamin $\mathrm{D}$ is associated with lower relapse risk in multiple sclerosis. Ann Neurol. 2010;68:193-203.

29. Soilu-Hanninen M, Laaksonen M, Laitinen I, Eralinna JP, Lilius EM, Mononen I. A longitudinal study of serum 25-hydroxyvitamin D and intact parathyroid hormone levels indicate the importance of vitamin D and calcium homeostasis regulation in multiple sclerosis. J Neurol Neurosurg Psychiatry. 2008;79:152-7.

30. Knekt P, Kilkkinen A, Rissanen H, Marniemi J, Saaksjarvi K, Heliovaara M. Serum vitamin D and the risk of Parkinson disease. Arch Neurol.2010;67:808-11.

31. Llewellyn DJ, Lang IA, Langa KM, et al. Vitamin $\mathrm{D}$ and risk of cognitive decline in elderly persons. Arch Intern Med. 2010;170:1135-41.

32. Burton JM, Kimball S, Vieth R. A phase I/II doseescalation trial of vitamin D3 and calcium in multiple sclerosis. Neurology. 2010;74:1852-9.

33. Pozuelo-Moyano B, Benito-Leon J, Mitchell AJ, Hernandez-Gallego J. A systematic review of randomized, double-blind, placebo-controlled trials examining the clinical efficacy of vitamin $\mathrm{D}$ in multiple sclerosis. Neuroepidemiology. 2013;40:147-53.

34. Aloe L, Rocco ML, Bianchi P, Manni L. Nerve growth factor: from the early discoveries to the potential clinical use. J Transl Med. 2012;10:239.

35. Garcion E, Wion-Barbot N, Montero-Menei CN, Berger F, Wion D. New clues about vitamin D functions in the nervous system. Trends Endocrinol Metab. 2002;13:100-5.

36. Generini S, Tuveri MA, Matucci Cerinic M, Mastinu F, Manni L, Aloe L. Topical application of nerve growth factor in human diabetic foot ulcers. A study of three cases. Exp Clin Endocrinol Diabetes. 2004;112:542-4. 
Mohamed Shaheen Anodiyil et al; Sch J App Med Sci, Jan, 2021; 9(1): 142-148

37. Apfel SC, Kessler JA, Adornato BT, Litchy WJ, Sanders C, Rask CA. Recombinant human nerve growth factor in the treatment of diabetic polyneuropathy. NGF Study Group. Neurology. 1998;51:695-702

38. Apfel SC, Schwartz S, Adornato BT. Efficacy and safety of recombinant human nerve growth factor in patients with diabetic polyneuropathy: a randomized controlled trial. rhNGF Clinical Investigator Group. JAMA. 2000;284:2215-21.

39. Shaw J, Zimmet P. The epidemiology of diabetic neuropathy. Diabetes Revs. 1999;7:245-52.

40. Skljarevski V, Malik RA. Clinical diagnosis of diabetic neuropathy. In: Veves AMR, editor. Diabetic neuropathy: clinical management. $2^{\text {nd }}$ ed. New Jersey: Humana; 2007.

41. Tavakoli M, Asghar O, Alam U, Petropoulos IN, Fadavi H, Malik RA. Review: novel insights on diagnosis, cause and treatment of diabetic neuropathy: focus on painful diabetic neuropathy. Ther Adv Endocrinol Metab. 2010;1:69-88.

42. Abbott CA, Malik RA, van Ross ER, Kulkarni J, Boulton AJ. Prevalence and characteristics of painful diabetic neuropathy in a large communitybased diabetic population in the UK. Diabetes Care. 2011;34:2220-4.

43. Tahrani AA, Ball A, Shepherd L, Rahim A, Jones AF, Bates A. The prevalence of vitamin D abnormalities in South Asians with type 2 diabetes mellitus in the UK. Int J Clin Pract. 64:351-5.

44. Cohen JA, Jeffers BW, Faldut D, Marcoux M, Schrier RW. Risks for sensorimotor peripheral neuropathy and autonomic neuropathy in noninsulin-dependent diabetes mellitus (NIDDM). Muscle Nerve. 1998;21:72-80.

45. Sorensen L, Molyneaux L, Yue DK. Insensate versus painful diabetic neuropathy: the effects of height, gender, ethnicity and glycaemic control. Diabetes Res Clin Pract. 2002;57:45-51.

46. Agmon-Levin N, Kivity S, Tzioufas AG. Low levels of vitamin-D are associated with neuropathy and lymphoma among patients with Sjogren's syndrome. J Autoimmun. 2012;39:234-9.

47. Straube S, Andrew Moore R, Derry S, McQuay HJ. Vitamin D and chronic pain. Pain. 2009;141:10-3.

48. Plotnikoff GA, Quigley JM. Prevalence of severe hypovitaminosis D in patients with persistent, nonspecific musculoskeletal pain. Mayo Clinic Proc. 2003;78:1463-70.

49. Soderstrom LH, Johnson SP, Diaz VA, Mainous AG 3rd. Association between vitamin D and diabetic neuropathy in a nationally representative sample: results from 2001-2004 NHANES. Diabet Med. 2012;29:50-5.

50. Shehab D, Al-Jarallah K, Mojiminiyi OA, Al Mohamedy H, Abdella NA. Does vitamin D deficiency play a role in peripheral neuropathy in type 2 diabetes? Diabet Med. 2012;29:43-9.

51. Skalli S, Muller M, Pradines S, Halimi S, WionBarbot N. Vitamin D deficiency and peripheral diabetic neuropathy. Eur J Intern Med. 2012;23:e67-8. 24 Diabetes Ther (2016) 7:11-26

52. Celikbilek A, Gocmen AY, Tanik N. Decreased serum vitamin D levels are associated with diabetic peripheral neuropathy in a rural area of Turkey. Acta Neurol Belg. 2015;115:47-52.

53. Alamdari A, Mozafari R, Tafakhori A. Esteghamati A. An inverse association between serum vitamin D levels with the presence and severity of impaired nerve conduction velocity and large fiber peripheral neuropathy in diabetic subjects. Neurol Sci. 2015;36(7):1121-6.

54. Lv WS, Zhao WJ, Gong SL. Serum 25hydroxyvitamin D levels and peripheral neuropathy in patients with type 2 diabetes: a systematic review and meta-analysis. J Endocrinol Invest. 2015;38:513-8.

55. Bell DSH. Reversal of the symptoms of diabetic neuropathy through correction of vitamin D deficiency in a type 1 diabetic patient. Case Rep Endocrinol. 2012; 2012:3.

56. Lee P, Chen R. Vitamin D as an analgesic for patients with type 2 diabetes and neuropathic pain. Arch Intern Med. 2008; 168:771-2.

57. Tavakoli M, Asghar O, Alam U, Petropoulos IN, Fadavi H, Malik RA. Novel insights on diagnosis, cause and treatment of diabetic neuropathy: focus on painful diabetic neuropathy. Ther Adv Endocrinol Metab. 2010;1:69-88.

58. Valensi P, Le Devehat C, Richard JL. A multicenter, double-blind, safety study of QR-333 for the treatment of symptomatic diabetic peripheral neuropathy. A preliminary report. J Diabetes Complications. 2005;19:247-53.

59. Boulton AJ, Vileikyte L, Ragnarson-Tennvall G, Apelqvist J. The global burden of diabetic foot disease. Lancet. 2005;366: 1719-24.

60. Zubair M, Malik A, Meerza D, Ahmad J. 25Hydroxyvitamin D [25(OH)D] levels and diabetic foot ulcer: is there any relationship? Diabetes Metab Syndr. 2013; 7:148-53.

61. Tiwari S, Pratyush DD, Gupta B. Prevalence and severity of vitamin D deficiency in patients with diabetic foot infection. Br J Nutr. 2013; 109:99102.

62. Hollis BW, Wagner CL. Clinical review: the role of the parent compound vitamin $\mathrm{D}$ with respect to metabolism and function: why clinical dose intervals can affect clinical outcomes. J Clin Endocrinol Metab. 2013; 98(12):4619-4628

63. Feldman D, Krishnan AV, Swami S, Giovannucci E, Feldman BJ. The role of vitamin D in reducing cancer risk and progression. Nat Rev Cancer.2014; 14(5):342-357

64. Van Belle TL, Gysemans C, Mathieu C. Vitamin D and diabetes: the odd couple. Trends Endocrinol Metab. 2013; 24(11):561-568

65. Pludowski P, Holick MF, Pilz S. Vitamin D effects on musculoskeletal health, immunity, autoimmunity, cardiovascular disease, cancer, 
Mohamed Shaheen Anodiyil et al; Sch J App Med Sci, Jan, 2021; 9(1): 142-148

fertility, pregnancy, dementia and mortality-a review of recent evidence. Autoimmun Rev. 2013; 12(10):976-989

66. Hurskainen AR, Virtanen JK, Tuomainen TP, Nurmi T, Voutilainen S. Association of serum 25hydroxyvitamin $\mathrm{D}$ with type 2 diabetes and markers of insulin resistance in a general older population in Finland. Diabetes Metab Res Rev. 2012; 28(5):418-423

67. Pinelli NR, Jaber LA, Brown MB, Herman WH. Serum 25-hydroxy vitamin $\mathrm{d}$ and insulin resistance, metabolic syndrome, and glucose intolerance among Arab Americans. Diabetes Care. 2010; 33(6):1373-1375

68. Callaghan BC, Cheng HT, Stables CL, Smith AL, Feldman EL. Diabetic neuropathy: clinical manifestations and current treatments. Lancet Neurol. 2012;11(6):521-534

69. Donath MY, Shoelson SE. Type 2 diabetes as an inflammatory disease. Nat Rev Immunol. 2011; 11(2):98-107

70. Verrotti A, Loiacono G, Mohn A, Chiarelli F. New insights in diabetic autonomic neuropathy in children and adolescents. Eur J Endocrinol. 2009; 161(6):811-818 